\title{
ALL IN ONE SYSTEM \\ (Pendekatan dan Prinsip Psikologis Pengajaran Bahasa Arab Terintegrasi)
}

\author{
Oleh: Muhammad Rusydi Rasyid*
}

\begin{abstract}
Learning a language particularly Arabic may at first sight look complex, demanding and time consuming. That is why Mukti Ali, the former Minister of Religious Affair, has come up with the idea of having several points of entry to language approach, called All in One System. Teaching Arabic as a Foreign Language - with appropriate techniques - to students who are not native speakers will enable them to learn Arabic effectively. It firstly develops a curriculum for Islamic secondary learners. This approach-All in One System-asserts that to create an effective teaching program it is not enough merely to use the most sophisticated technology such as CD's, and phonetics software. Teaching methods tested in actual conditions are even more important. The process for teaching Arabic to non native speakers is very different from teaching other languages. Therefore, the concept built on teaching Arabic to introduce integrated four skills at once-listening, reading, speaking, and writing is of great importance.
\end{abstract}

KEYWORDS: All in One System, pendekatan psikologis, pengajaran

METODOLOGI pengajaran bahasa tidak pernah statis, ia berkembang sejalan dengan kemajuan teknologi. Bukan hanya penerapan integrasi teknologi dalam pengajaran bahasa, melahirkan berbagai pendekatan psikologi ikut dilibatkan dalam rangka proses akselarasi language acquisition. Bahkan, memasuki abad ke-20 pengajaran bahasa, tidak terkecuali bahasa Arab, dikombinasikan dengan aspek psikologi, sehingga muncul banyak metode pengajaran bahasa yang berbasis psikologi, seperti Suggestopedia, Total Physical Response, the Silent Way, Counseling Learning Method (CLM) dan seterusnya. ${ }^{1}$ Namun, di balik banyaknya metode pengajaran bahasa Arab, masih dijumpai fakta dimana banyak pengajar/guru yang

*Magister dalam bidang Pendidikan Islam ini adalah lulusan Program Pascasarjana IAIN Alauddin Makassar tahun 2001. Ia meraih magister kedua kalinya pada Faculty of Education Curtin University of Technology Western Australia tahun 2004. Dosen Fakultas Tarbiyah dan Keguruan UIN Alauddin ini sedang menjabat sebagai Sekretaris Project Management Unit of UIN Alauddin of Islamic Development Bank (PMU-IDB). 
lebih senang menggunakan pengajaran bahasa dengan sistem klasik, yaitu metode baca kemudian terjemah. ${ }^{2}$ Diakui, kedua cara ini memang sangat menguntungkan bagi pengajar, tidak perlu banyak persiapan, tidak perlu mengerti metodologi pengajaran, bahkan tanpa memiliki sedikitpun ilmu psikologi mengajar, ia dapat mengeksekusi pengajaran sederhana yang hanya berbasis old experience tanpa dipoles teaching based method. Sangat ironi, di tengah saratnya metode dan mudahnya memperoleh akses informasi pengajaran, dimana orang berlomba untuk mempercepat pemerolehan bahasa degan sejumlah metodologi dan media pengajaran, ada saja pengajar yang bernostalgia dengan gaya mengajar klasiknya. Sehingga terkesan, tidak ada perbedaan antara belajar istima', qawaid, ilmu lughah, dan ilmu bahasa Arab lainnya dengan mutalaah dan tarjamah karena metodenya peserta didik hanya disuruh membaca lalu diterjemahkan.

Jika piringan hitam diputar kembali untuk mereview sejarah pengajaran bahasa Arab sebelum sampai kepada pendekatan All in One Systemyang menjadi konsentrasi tulisan ini - akan terlihat bahwa sebelum sistem pengajaran bahasa Arab bersentuhan dengan metode pengajaran bahasa modern, maka bahasa Arab diajarkan dengan cara yang sangat sederhana dan bertumpu pada metode tarjamah dengan mengandalkan buku-buku agama yang tertulis dalam bahasa Arab. Dengan begitu, waktu yang dibutuhkan untuk mengetahui bahasa Arab itu sangat lama dan panjang. Sistem penjenjangan pada waktu itu belum dikenal, bahkan pengajarannya masih bersifat khalaqah (non classical).

Setelah melalui beberapa fase dan abad, akhirnya pengajaran bahasa Arab memasuki era modern, yakni mulai bersentuhan dengan sistem pengajaran yang ada di Eropa, ${ }^{3}$ terutama setelah pemikir-pemikir Barat yang khusus melakukan kajian-kajian ketimuran mulai mencurahkan pemikirannya terhadap Islam, ${ }^{4}$ tentu saja dengan beragam motif mempelajarinya, maka usaha-usaha untuk mempermudah dalam mempelajari dan mengajarkan bahasa Arab sebagai foreign language mulai digalakkan.

Pada bulan Maret 1904 untuk pertama kalinya terbit sebuah buku yang berjudul How to Teach a Foreign Language yang pada saat itu dianggap sangat representatif dipergunakan untuk pengajaran bahasa asing. Buku itu sudah mulai membahas beberapa cara mengajarkan bahasa asing serta kemampuan-kemampuan bahasa pada saat itu mulai ditawarkan, yaitu kemampuan menyimak, membaca, mengekspresikan ide, dan menulis. Akan tetapi, buku tersebut hanya sebatas menawarkan teknik pengajaran bahasa Inggris dan Latin, tidak menyentuh sama sekali pengajaran bahasa Arab. ${ }^{5}$ Menurut hemat penulis, boleh jadi buku ini serta beberapa buku yang terbit kemudian telah menjadi inspirasi untuk mengadopsi metode pengajaran bahasa Inggris ke dalam bahasa Arab. 
Pada tahun 1970, seorang guru besar-baca Professor-bahasa Arab dari Universitas Oxford di Inggris menulis sebuah buku tentang bahasa Arab. Dalam buku tersebut, ia menawarkan sebuah metodologi pengajaran bahasa Arab dengan metode gramatika. Akan tetapi, ini dikhususkan bagi mereka yang sudah memiliki pengetahuan dasar bahasa Arab terutama penguasaan kosa kata bahasa Arab. Metode yang diperkenalkannya hampir sama dengan cara mengajarkan tata bahasa Inggris yang sudah disederhanakan sehingga kesan qawaid yang rumit (qawaid sentries) ditiadakan. ${ }^{6}$

Di Indonesia, pada permulaan abad ke-20, pengajaran bahasa Arab terintegrasi dengan pembaruan pendidikan Islam yang bertumpu pada penerapan sistem klasikal, kurikulum, penjenjangan pendidikan dan pemberian syahadah (ijazah) yang dianggap sangat perlu dan mutlak adanya. ${ }^{7}$ Dari sinilah sistem pengajaran bahasa Arab yang semula diajarkan di mesjid, langgar, dan rumah kiai ditransfer ke kelas, dan pada perkembangan selanjutnya diupayakan penyederhanaan cara mengajarkan bahasa Arab terhadap para peserta didik dalam artian menerapkan metode pengajaran bahasa asing dalam pengajaran bahasa Arab. Hal ini dimaksudkan untuk menciptakan perasaan senang dan ketertarikan dalam mempelajari bahasa Arab. Selain itu, juga dimaksudkan agar kesan sulit dan angker mempelajari bahasa sedapat mungkin dihilangkan atau diminimalkan. Selanjutnya, muncullah metode tarjamah, gramatika, direct method dan disusul dengan metode gado-gado (eklektik) dalam pengajaran bahasa Arab di Indonesia.

Dalam pengajaran bahasa asing secara separate (terpisah-pisah dari masing-masing bahagian) terdapat beberapa kelemahan bagi para guru dan peserta didik. Di samping mengajarkan materi kebahasaan itu sendiri, terget penyelesaian maddah harus rampung sebelum memasuki ujian semester karena kurikulum menghendaki demikian. Atas dasar tersebut, Mukti Ali-pada saat itu menduduki jabatan Menteri Agama RImengatakan bahwa penguasaan bahasa Arab sebagai bahasa yang penting dikuasai oleh mahapeserta didik IAIN masih sangat lemah. ${ }^{8}$ Ia lalu mengusulkan penerapan All in One System sebagai suatu pendekatan dalam pengajaran bahasa Arab.

Pendekatan ini, ${ }^{9}$ memandang bahwa pengajaran bahasa merupakan satu kesatuan yang tidak bisa dipisah-pisahkan atau dicabang-cabangkan (furū'iyyah). Pendekatan ini diterapkan mulai dari sekolah lanjutan tingkat pertama, menengah, sampai pada tingkat perguruan tinggi terutama oleh lembaga pendidikan negeri atau lembaga-lembaga yang mengikuti aturan main yang telah ditetapkan. Sebagai pendekatan yang terbilang baru, jika 
dibandingkan dengan beberapa metode yang telah mendahuluinya, maka sangat perlu diketahui terutama bagi mereka yang bergelut dalam dunia pengajaran bahasa.

\section{PENGERTIAN ALL IN ONE SYSTEM}

Secara etimologis, all berarti semua, seluruh atau setiap. ${ }^{10}$ All in one (dalam bentuk idiom) berarti semua ada. ${ }^{11}$ Sedangkan kata system adalah bentuk noun yang berarti sistem, susunan dan cara. ${ }^{12}$ Munir Ba'labaki mengatakan bahwa kata system itu bisa berarti thariqah, nizam, dan tartib,13 atau terjemahan secara harfiah All in One System adalah multi atau keseluruhan dalam satu sistem.

Adapun pengertian All in One System secara terminologis adalah sebuah sistem atau pendekatan dalam pengajaran bahasa yang memandang bahasa itu sebagai suatu kesatuan yang tidak bisa dipisah-pisahkan. ${ }^{14}$ Menurut Abd. Karim Hafid, All in One System adalah memandang bahasa yang diajarkan sebagai bagian yang terkemas dalam satu kesatuan bukan merupakan cabang yang terpisah-pisah dan berbeda-beda. ${ }^{15}$

Jadi, pendekatan All in One System adalah teori tentang pengajaran bahasa Arab secara integratif atau menyeluruh tanpa ada pemisahan dari masing-masing bagiannya - baca maharat - sehingga kemampuan listening, speaking, reading, dan writing dianggap satu kesatuan yang saling melengkapi tanpa dipisahkan oleh al-hissah tertentu. Pendekatan ini biasa pula diistilahkan dalam bahasa Arab dengan Nazhariyyah al-Wihhdah.

\section{PRINSIP-PRINSIP ALL IN ONE SYSTEM}

All in One System sebagai suatu pendekatan dalam pengajaran bahasa Arab merupakan gagasan A. Mukti Ali yang pada waktu itu menjabat sebagai Menteri Agama RI. Ia berpendapat bahwa pengajaran bahasa Arab itu harus diusahakan untuk menekankan keaktifan belajar pada peserta didik lebih besar. Untuk merealisasikan ide pengajaran bahasa Arab dengan menggunakan pendekatan All in One System pada tingkat IAIN, maka dibentuklah lembaga bahasa yang dilengkapi dengan laboratorium bahasa (language laboratory). Dalam penerapan pendekatan All in One System, pengajaran bahasa dipisahkan dari fakultas dan diberi penjenjangan (baca level) berupa tingkat elementary, intermediate, dan advance. Pada tahap selanjutnya, pendekatan All in One System itu diterapkan pula pada tingkat sekolah lanjutan pertama (Madrasah Tsanawiyah) dan sekolah lanjutan tingkat menengah (Madrasah Aliyah).16 Tentu saja dengan tidak mengabaikan prinsip-prinsip pengajaran bahasa Arab yang bisa 
menjadi pegangan bagi pengajar dalam melihat dan memantau kemampuan peserta didik dalam mentransfer bahasa yang diajarkan. ${ }^{17}$ Dengan demikian, tujuan pengajaran bahasa Arab sebagai bahasa asing bisa tercapai dan sesuai dengan hasil yang dikehendaki.

Tayyar Yusuf berpendapat bahwa dengan memperhatikan prinsipperinsip pengajaran bisa membantu terjadinya proses mengajar itu dengan baik dan mengarah pada sasaran yang dituju. Prinsip-prinsip itu terdiri dari apersepsi, motivasi, perhatian, dan individualitas yang kesemuanya saling terkait satu sama lain. ${ }^{17}$ Prinsip pengajaran yang sifatnya sangat general, bisa diterapkan dalam pengajaran bahasa Arab sebagai bahasa asing.

Mengajarkan bahasa Arab sebagai bahasa asing dengan menggunakan pendekatan All in One System tidak lepas dari prinsip-prinsip pengajaran bahasa yang di antaranya akan diuraikan sebagai berikut.

\section{Prinsip Psikologis}

Mengajarkan bahasa Arab di sekolah, terutama bagi peserta didik di sekolah menengah, guru diharuskan mempunyai kemampuan strategis psikologis untuk mengidentifikasi bagaimana dan kapan para peserta didik mampu belajar bahasa Arab dengan baik. Kemampuan ini akan memudahkan guru menciptakan strategi, metode, dan media pembelajaran yang tepat, sehingga peserta didik merasa tertarik dan tertantang untuk bisa menguasai bahasa Arab dengan baik. Belajar dan mengajar bahasa asing jelas membutuhkan strategi yang berbeda dengan ketika peserta didik belajar dan guru mengajarkan bahasa Indonesia sebagai bahasa ibu atau bahasa nasional. Guru perlu memahami aspek-aspek psikologis peserta didik agar mampu menciptkan proses pembelajaran yang lebih bermakna. Untuk bisa memahami aspek-aspek psikologis peserta didik dalam belajar bahasa, maka diperlukan pengetahuan guru yang memadai terhadap teori-teori psikologi yang relevan untuk mengajar bahasa. Pengetahuan guru terhadap teori-teori psikologi juga akan mengarahkan guru mengidentifikasi kapan dan dengan cara bagaimana peserta didik bisa belajar bahasa dengan baik.

Pengajaran bahasa Arab dengan menggunakan pendekatan ini-baca All in One System-diharapkan memacu kesegaran dan semangat belajar para peserta didik. Dengan begitu muncul motivasi untuk meningkatkan gairah belajar karena keragaman dalam pendekatan tersebut dan tidak monoton. ${ }^{19}$ Seorang guru yang baik adalah yang pandai memberi motivasi kepada peserta didik sehingga kesulitan-kesulitan yang dihadapi peserta didik dalam belajar bahasa Arab, baik yang disebabkan oleh faktor internal 
peserta didik, maupun faktor eksternal yang kemungkinan bisa mematikan semangatnya dalam belajar, dapat diatasi. ${ }^{20}$ Guru harus mampu memberikan pendekatan-pendekatan khusus dalam mengajar untuk mengakomodasi individual differences pada setiap peserta didik. ${ }^{21}$ Mengingat peserta didik yang dihadapi dalam kelas mempunyai keingian dan kemampuan yang berbeda-beda, maka dibutuhkan stimulus dan reinforcement yang dilakukan oleh guru secara sustainable.22 Pendekatan All in One System mampu memberi dorongan dan menumbuhkan minat peserta didik belajar bahasa Arab. Review secara berulang-ulang yang diberikan oleh guru setiap selesai satu materi untuk dipecahkan mampu menjadikan peserta didik lebih mantap dan lebih paham akan materi kebahasaan tersebut. Pengulangan materi serta latihan-latihan yang diberikan oleh pengajar akan lebih berkesan kepada peserta didik, bahkan membantu percepatan pemerolehan bahasa secara otomatis. Dalam pendekatan ini sedapat mungkin pengajar tidak menimbulkan kesan bahwa belajar bahasa itu susah, tetapi harus ditanamkan dalam benak peserta didik bahwa mempelajari bahasa Arab tidaklah sesulit yang mereka bayangkan. Oleh karena itu, pengajar disarankan pada saat mengajar tidak monoton ke materi semata, tetapi harus diselingi upaya memotivasi peserta didik dengantentu saja-menggunakan bahasa Arab. ${ }^{23}$ Prinsip guru tidak ada satupun bagian yang terlewatkan meskipun hanya contoh sederhana, tetapi selalu terkait dengan bahasa Arab. Jika pengajar memberikan materi bacaan meskipun hanya dua baris, maka dalam aspek all in one selalu terintegrasi arba'ah maharat, meliputi istimā', qirā'ah, muhādatsah, dan kitābah.

Pergantian fase perlu sekali dilakukan pada saat mengajar bahasa. Langkah ini perlu dilakukan mengingat pada umumnya kemampuan manusia untuk berkonsentrasi penuh atas suatu fenomena hanyalah kurang lebih dua puluh menit. Tentu tidak mudah untuk mengalihkan kebiasaan mengajar teacher centered, berpusat pada guru, menjadi student centered, berpusat pada peserta didik. Metode ini menuntut beberapa hal dari peserta didik, misalnya spontanitas, aktivitas, keberanian menanggung resiko serta tanggung jawab. Meskipun begitu hendaknya para pengajar tidak berputus asa untuk dengan sabar mencoba membiasakan peserta didik berperan aktif dalam proses pembelajaran. Dengan begitu, peserta didik perlu diajak untuk menemukan sendiri jawaban yang mereka butuhkan-inductive method. Hal ini akan menjadi kebanggaan tersendiri bagi mereka, sehingga semakin termotivasi untuk belajar bahasa Arab.

\section{Prinsip Pedagogis}

Seorang guru yang mengajarkan bahasa dengan pendekatan All in

One System harus tahu bahwa materi pelajaran yang satu dengan yang 
lainnya saling terkait terutama untuk melatih empat skills kebahasaan yakni listening, reading, speaking dan writing sehingga perkembangan bahasa pelajar itu bisa berimbang dan diselesaikan/dikerjakan dalam satu situasi yang sama, tanpa ada pemisahan pemberian penguasaan salah satu dari empat skill tersebut. ${ }^{24}$ Menurut Radhi al-Hafid, pendekatan All in One System sangat cocok dipelajari dengan menggunakan teori Gestalt secara berimbang pada waktu yang sama. ${ }^{25}$ Teori ini mempunyai prinsip bahwa belajar itu berdasarkan pada keseluruhan, suatu perkembangan, terjadi transfer, lebih berhasil bila sesuai dengan minat, dan dilaksanakan secara berkesinambungan. ${ }^{26}$

Dengan mengajarkan materi bahasa Arab secara terintegrasi, pengajar harus bijak menghadapi peserta didik baik pada saat memberikan materi atau memberikan latihan tulisan dan lisan karena empat skill menjadi target yang ingin dicapai oleh guru secara holistik. Seorang guru seharusnya mentoleransi kesalahan yang dilakukan peserta didik, karena boleh jadi kesalahan tersebut terjadi karena ketidaksengajaan atau memang belum sampai kepada taraf mengerti. Mentoleransi kesalahan bukan berarti pengajar mendiamkan saja kesalahan yang dibuat oleh peserta didik, melainkan membicarakan dan mengoreksinya sesuai dengan tujuan latihan. Koreksi kesalahan hendaknya sesuai dengan tujuan latihan terkait. Misalnya, pada saat peserta didik memberikan jawaban dalam bentuk pertanyaan-pertanyaan yang saling terkait, sebaiknya guru tidak memotong untuk mengoreksi atau sebaiknya kesalahan tidak dikomentari karena hal ini akan mengacaukan konsentrasi peserta didik atas apa yang akan disampaikannya. Kesalahan adalah normal. Tidak seorangpun berniat untuk membuatnya. Suatu jawaban walaupun salah adalah hasil suatu usaha. Di samping itu kesalahan juga mempunyai arti diagnosis bagi guru, karena dengan menganalisa suatu kesalahan, guru dapat menemukan letak kelemahan dalam penguasaan materi. Pujian, bantuan, dan penghargaan atas usaha peserta didik biasanya mempertebal rasa percaya diri mereka dan meningkatkan saling percaya antara peserta didik dan guru. Sebaliknya, kritik dari pihak guru yang berlebihan kadang-kadang lebih memungkinkan mendatangkan rasa kuatir dan takut untuk membuat kesalahan ketika peserta didik akan mengemukakan pendapatnya, sehingga kreativitas mereka terganggu. Sebaiknya kritik semacam ini dihindari oleh para pengajar.

Apabila pada diri peserta didik terdapat rasa khawatir dan takut salah untuk mengemukakan pendapatnya yang akhirnya dapat mengganggu konsentrasi dan kreativitasnya, maka proses interaksi sosial di dalam kelas akan terganggu sehingga harapan untuk berinteraksi dengan bahasa yang diajarkan sulit untuk dicapai. 


\section{Prinsip Linguistik}

Prinsip All in One System sejalan dengan aktivitas mendengar, berbicara dan menulis. Ketika pembicara ingin mengekspresikan sebuah ide karena ada stimulus dari pendengaran, maka ada usaha untuk membahasakannya apakah ia berupa bahasa lisan ataupun bahasa tulisan. ${ }^{27}$ Prinsip linguistik bahasa menyatakan bahwa bahasa itu adalah hasil dari ide-ide yang diekspresikan melalui lisan, bukan dipenjarakan dalam lubuk hati yang tidak bisa terkomunikasikan dan tidak melibatkan fungsi-fungsi bahasa. ${ }^{28}$

Oleh karena itu, jika guru berharap agar peserta didik dapat berkomunikasi dalam bahasa Arab dengan baik, maka guru harus bebahasa Arab di kelas sebab scaffolding talk-pembicaraan yang bukan pelajaran. Inilah yang bisa menciptakan pembiasaan untuk berkomunikasi dalam bahasa Arab bagi peserta didik. Kelemahan umum guru-guru bahasa Arab di Indonesia dalam hal melakukan scaffolding talk perlu disadari dengan benar, karena kenyataanya guru yang mengajar bahasa Arab tetapi di dalam kelas justru lebih banyak berbicara dalam bahasa Indonesia. Keadaan ini memang terdengar ironis, tetapi ini tidak berarti bahwa kurikulum harus menyesuaikan dengan keadaan guru. Dalam hal ini All in One System tampil sebagai solusi dari kendala komunikasi baik lisan maupun tulisan.

\section{TEKNIK PENGAJARAN ALL IN ONE SYSTEM}

All in One System lebih applicable diterapkan pada peserta didik tingkat elementary dan intermediate. ${ }^{29}$ Adapun untuk tingkat advance pengajaran bahasa itu lebih cocok menggunakan nazhariyyah al-furü'. Pendekatan teori kesatuan-baca All in One System-bisa menggunakan beragam metode pengajaran bahasa asing tergantung bagaimana guru memodifikasi kelas yang dihadapinya dengan tetap berpegang pada pencapaian Mahārāt alArba'ah.

Pada pertama kalinya seorang guru memulai langkahnya dengan memberi pengenalan bahasa Arab kepada peserta didik apakah dengan cara memperdengarkan kalimat bahasa Arab itu dengan menggunakan alat bantu pengajaran-baca media pengajaran-atau guru itu sendiri yang mengucapkan langsung kalimat-kalimat tersebut. Hal ini berguna untuk membuat peserta didik familiar akan tata bunyi bahasa Arab. ${ }^{30}$

Kemudian guru beralih kepada cara mengucapkan huruf-huruf Arab satu persatu, lalu kata demi kata, dan kalimat demi kalimat. Selanjutnya beralih kepada latihan percakapan dengan memberi contoh-contoh 
percakapan kepada peserta didik. Diusahakan menggunakan ungkapanungkapan sehari-hari-yang menyentuh kehidupan sehari-hari-agar bahasa yang dipergunakan peserta didik tersebut bisa hidup. ${ }^{31}$

Membaca merupakan salah satu kunci utama mengajarkan seseorang berbicara. ${ }^{32}$ Oleh karena itu, latihan membaca tidak boleh lepas dari pemantauan guru karena bagaimanapun seorang peserta didik yang mempelajari bahasa Arab, tujuan akhirnya adalah mengetahui ilmu-ilmu agama Islam yang hanya dapat dipenuhi jikalau peserta didik mampu membaca bahasa Arab. Dengan membiasakan peserta didik mendengar istilah-istilah yang baru dan melakukan ta'bir-ta'bir yang baik akan mempengaruhi kemampuan membaca mereka. ${ }^{33}$ Guru yang mengajarkan qirä'ah kepada peserta didik harus pandai-pandai mencari materi-materi yang menarik bagi mereka untuk menghindari terjadinya kebosanan dalam mengkonsumsi materi tersebut. Kisah-kisah yang sifatnya lucu, menarik, dan mendidik bisa menjadi solusinya. Misalnya, seorang guru mengambil beberapa maudh $\bar{u}^{\prime}$ dari buku al-Qissah fi al-Tarbiyyah, selanjutnya diberikan kepada peserta didik untuk dibaca. ${ }^{34}$

Selanjutnya, peserta didik dilatih mengekspresikan isi hatinya atau apa yang terlintas di benaknya dalam bentuk bahasa tulisan. Pada awalnya ia dilatih menterjemah kalimat-kalimat bahasa Indonesia ke dalam bahasa Arab. Kemudian berkembang kepada memberi sebuah topik ringan - baca sederhana-untuk dibuat karangan (insyā') dan selanjutnya memberi kebebasan untuk menentukan judul karangan yang akan dibuatnya.

Guru juga boleh memberikan atau mengisi peserta didik dengan alqawā'id al-'ammah (general structure) atau kaidah-kaidah dasar pada setiap tahap. Dari sini peserta didik bisa mendapat patron dalam mempelajari bahasa sehingga kesan kesalahan yang banyak sedapat mungkin bisa ditekan.

Pengajar sedapat mungkin menciptakan iklim pengajaran bahasa dalam bentuk interaksi yang komunikatif dalam kelas-classroom climatedengan membawa materi yang bisa membawa aspek-aspek dari luar ke dalam kelas. Menciptakan suasana hubungan interaksi sosial di dalam kelas mencerminkan sikap guru sebagai fasilitator proses pembelajaran dan semakin jauh dari sikap guru yang mengarah kepada tindakan otoriter. Dengan begitu, perasaan takut dan malu untuk mengutarakan pendapat dan pertanyaan dengan menggunakan bahasa Arab yang diajarkan, secara spontan akan hilang dan mereka seolah-olah terlibat langsung kapan dan di mana bahasa Arab itu digunakan. 


\section{KESIMPULAN}

Dari uraian yang telah dikemukakan di atas dapat disimpulkan ke dalam empat hal berikut:

1. All in One System merupakan sebuah pendekatan dalam pengajaran bahasa Arab yang memandang bahasa sebagai kesatuan yang terintegrasi satu sama lain, sehingga prinsip pencabangan tidak dikenal.

2. Pendekatan All in One System sebagai sebuah asumsi dasar pengajaran bahasa berpegang pada prinsip-prinsip pengajaran bahasa asing yaitu prinsip psikologis, prinsip pedagogis, dan prinsip linguistik.

3. Menggunakan All in One System dalam mengajarkan bahasa Arab tetap merujuk kepada teknik pengajarannya atau langkah-langkahnya yaitu mengajarkan latihan pengucapan, kemudian latihan percakapan dan selanjutnya melatih kemahiran membaca lalu beralih kepada latihan mengekspresikan ide dalam bentuk tulisan (kitābah).

4. Pendekatan All in One System sangat tepat diterapkan pada sistem pengajaran bahasa Arab intensif karena semua aspek kemahiran bisa terakomodasi dalam satu jenjang pengajaran dan sistem pengajarannya berdasarkan pada teori kesatuan.

\section{CATATAN AKHIR:}

1. Lihat Azhar Arsyad, Bahasa Arab dan Metode Pengajarannya: Beberapa Pokok Pikiran, cet. I, Yogyakarta: Pustaka Pelajar, 2003, h. 23-30.

2. John Bigs dan Ros Tefler, The Process of Learning, Cetakan kedua, Sydney: Prantice Hall, 1989, h. 407.

3. Lihat Radhi al-Hafid, Pengembangan Materi dan Metode Pengajaran Bahasa Arab, Ujungpandang: Berkah, 1993, h. 12.

4. Tokoh orientalis yang bernama Ignaz Goloziher (1850-1921) dianggap sebagai pendiri studi-studi Islam (Islamic Studies) di Barat. Ia berkebangsaan Hongaria, kemudian muncul nama Snouck Horgrunje (1857-1936). Kemudian bermunculan tokoh-tokoh orientalis lain yang berusaha mempelajari Islam dengan memperkenalkan bahasa Arab. Lihat H.L. Beck dan N.S.G. Kaptein (redaktur), Pandangan Barat Terhadap Literatur Hukum, Filosof, Teologi, dan Mistik Tradisi Islam, Jilid I, Jakarta: INIS, 1988, h. iv.

5. Lihat Otto Jesperson, How to Teach a Foreign Language, cet. XIII, London: George Allen \& Unwin LTD, 1967, h. 179-180.

6. Di samping memperkenalkan metode gramatika (qawaid), Beeston juga memperkenalkan sistem transiliterasi yakni teknik penulisan huruf suatu bahasa ke dalam bahasa lain untuk menampilkan kata-kata asal yang seringkali tersembunyi oleh pelafalan bunyi karena keterbatasan bunyi huruf- huruf yang dipunyai oleh suatu bahasa, lihat A.F.L Buston, Buston the Arabic Language Today, cet. I, London: Hutchinson \& CO, 1970, h. 12-29. Bandingkan pula dengan M. Quraish Shihab, Membumikan al-Qur'an, Fungsi dan Peran Wahyu dalam Kehidupan Masyarakat, cet. XV, Bandung: Mizan, 1997, h. 10. 
7. Lihat Radhi al-Hafid, Metode Pengajaran Bahasa Arab, Ujungpadang: IAIN Alauddin, t.th., h. 5.

8. Lihat Azyumardi Azra, Esei-Esei Intelektual Muslim dan Pendidikan Islam, cet. I, Jakarta: Logos Wacana Ilmu, 1998, h. 139.

9. Yang dimaksud dengan pendekatan (approach) adalah rangkaian asumsi tentang hakekat pengajaran dan belajar bahasa yang sifatnya aksiomatis. Lihat Muljanto Sumardi, Pengajaran Bahasa Asing, Jakarta: Bulan Bintang, t.th, h. 11.

10. Lihat Peter Salim, Advance English Indonesian Dictionary Student's Edition, cet. III; Jakarta: Modern English Press, 1991, h. 25.

11. Lihat John M. Echols dan Hassan Shadily, Kamus Inggris Indonesia, cet. XX, Jakarta: Gramedia, 1995, h. 23.

12. Lihat, Ibid., h. 575.

13. Lihat Munir Ba'labaki, al-Maurid A Modern English Arabic Dictionary, Beirut Dar al-Ilm li al-Malayin, 1985, h. 941.

14. Chatibul Umam, et al., Pedoman Pengajaran Bahasa Arab pada Perguruan Tinggi Agama/IAIN, Jakarta: Proyek Pengembangan Sistem Pendidikan Agama Departemen Agama RI, 1975, h. 173.

15. Lihat Abd. Karim Hafid, "Pengembangan Metode Pembelajaran Bahasa Arab", Makalah, Disampaikan pada Seminar Metodologi Pembelajaran Bahasa Arab tanggal 22-24 April 1999, h. 1. Bandingkan pula dengan Radhi al-Hafid, Metode, h. 55-56.

16. Lihat Radhi al-Hafid, Pengembangan Materi dan Metode Pengajaran Bahasa Arab, h. 98.

17. Lihat Mahmud Kamil al-Naqah, Ta'lim al-Lugah al-'Arabiyyah li al-Näthiqin bi Lugat Ukhrā: Ususuh, Madākhiluh, Thuruq Tadrīs, Makkah al-Mukarramah: Jamiah Um al-Qura', 1985, h. 50.

18. Lihat Tayyar Yusuf dan Saiful Anwar, Metodologi Pengajaran Agama dan Bahasa Arab, cet. I, Jakarta: Raja Grafindo Persada, 1995, h. 95.

19. Wright T., Roles of Teachers and Learners, Oxford: Oxford University Press, 1987, h. 43.

20. Lihat Chatibul Umam, et. al., op.cit., h. 173.

21. Paul Eggen dan Don Kauchack, Educational Psychology: Classroom Connections, New York: Macmillan College, 1994, h. 180.

22. Susan Groundwater, dkk., Teahning Challenges and Dilemmas, New South Wales: Harcourt Brace, 1998, h. 54.

23. Lihat Muhibuddin Syah, Psikologi Pendidikan Suatu Pendekatan Baru, cet. II, Bandung: Remaja Rosdakarya, 1995, h. 173-174.

24. Lihat Chatibul Umam, et.al., op.cit., h. 174.

25. Lihat Radhi al-Hafid, Pengembangan Materi dan Metode Pengajaran Bahasa Arab, h. 43.

26. Lihat Slameto, Belajar dan Faktor-faktor yang Mempengaruhinya, cet. II, Jakarta: Rineka Cipta, 1991, h. 10-12.

27. Lihat A. Akrom Malibary, Pengajaran Bahasa Arab di Madrasah Aliyah, Tinjauan Metodologi Sekilas, cet. I, Jakarta: Bulan Bintang, 1987, h. 2.

28. Lihat Bambang Yudi Cahyono, Kristal-kristal Ilmu Bahasa, cet. I, Surabaya: Airlangga University Press, 1995, h. 315. 
29. Lihat Radhi al-Hafid, Pengembangan Materi dan Metode Pengajaran Bahasa Arab, h. 43.

30. Lihat Chatibul Umam, et.al., op.cit., h. 175.

31. Lihat, Ibid., h. 179-180.

32. Lihat, Ibid., h. 181.

33. Lihat Muhammad Abd al-Qadir Ahmad, Thuruq Ta'lim al-Lughah al-'Arabiyyah, cet. I, al-Qahirah: Maktabah al-Nahdah al-Misriyah, 1979, h. 112.

34. Teknik pengajaran cerita-cerita yang sifatnya humor, mendidik dan lain-lain dengan menggunakan metode qirä'ah dapat terlihat pada Abd. Azis Abd. AlMajid, al-Qishshah fi al-Tarbiyyah Ushūluhā al-Nafsiyyah, Tathawwurruhā, Maddatuhā wa Tharīqah Sardihā, cet. VIII, Mesir: Dar al-Maarif, 1976, h. 9-65.

\section{DAFTAR PUSTAKA:}

Abd al-Majid, Abd al-Azis, Al-Qishshah fi al-Tarbiyyah Ushūluhā al-Nafsiyyah, Tathawwurruhā, Maddatuhā wa Tharīqah Sardihā, cet. VIII, Mesir: Dar alMaarif, 1976.

Ahmad, Muhammad Abd al-Qadir, Thuruq Ta'lim al-Lughah al-'Arabiyyah, cet. I, alQahirah Maktabah al-Nahdah al-Misriyah, 1979.

Arsyad, Azhar. Bahasa Arab dan Metode Pengajarannya: Beberapa Pokok Pikiran, cet. I, Yogyakarta: Pustaka Pelajar, 2003.

Azra, Azyumardi, Esei-Esei Intelektual Muslim dan Pendidikan Islam, cet. I, Jakarta: Logos Wacana Ilmu, 1998.

Ba'labaki, Munir, Al-Maurid A Modern English Arabic Dictionary, Beirut Dar al-Ilm li al-Malayin, 1985.

Beck H.L. dan N.S.G. Kaptein (redaktur), Pandangan Barat Terhadap Literatur Hukum, Filosof, Teologi, dan Mistik Tradisi Islam, jilid I, Jakarta: INIS, 1988.

Beeston, A.F.L., The Arabic Language Today, cet. I, London: Hutchinson \& CO, 1970.

Bigs, John dan Ros Tefler, The Process of Learning, cet. II, Sydney: Prantice Hall, 1989.

Echols, John M. dan Hassan Shadily, Kamus Inggris Indonesia, cet. XXI, Jakarta: Gramedia, 1995.

Eggen, Paul dan Don Kauchack, Educational Psychology: Classroom Connections, New York: Macmillan College, 1994.

Groundwater, Susan. dkk., Teahning Challenges and Dilemmas, New South Wales: Harcourt Brace, 1998.

al-Hafid, Radhi. Metode Pengajaran Bahasa Arab, Ujungpandang: IAIN Alauddin, t.th.

--------, Pengembangan Materi dan Metode Pengajaran Bahasa Arab, Ujungpandang: Berkah, 1993.

Hafid, Abd. Karim, "Pengembangan Metode Pembelajaran Bahasa Arab", Makalah, disampaikan pada Seminar Metodologi Pembelajaran Bahasa Arab tanggal 22-24 April 1999.

Jesperson, Otto, How to Teach a Foreign Language, cet. XIII, London: George Allen \& Unwin LTD, 1967. 
Malibary, A. Akrom, Pengajaran Bahasa Arab di Madrasah Aliyah, Tinjauan Metodologi Sekilas, cet. I, Jakarta: Bulan Bintang, 1987.

al-Naqah, Mahmud Kamil, Ta'lìm al-Lugah al-'Arabiyyah li al-Nāthiqīn bi Lugat Ukhrā: Ususuh, Madākhiluh, Thuruq Tadrīs, Makkah al-Mukarramah: Jamiah Um al-Qura', 1985.

Salim, Peter, Advance English Indonesian Dictionary Student's Edition, cet.III, Jakarta: Modern English Press, 1991.

Shihab, M. Quraish, Membumikan al-Qur'an, Fungsi dan Peran Wahyu dalam Kehidupan Masyarakat, cet. XV, Bandung: Mizan, 1997.

Slameto, Belajar dan Faktor-faktor yang Mempengaruhinya, cet. II, Jakarta: Rineka Cipta, 1991.

Sumardi, Muljanto, Pengajaran Bahasa Asing, Jakarta: Bulan Bintang, t.th.

Syah, Muhibuddin, Psikologi Pendidikan Suatu Pendekatan Baru, cet. II, Bandung: Remaja Rosdakarya, 1995.

Umam, Chatibul, et. al., Pedoman Pengajaran Bahasa Arab pada Perguruan Tinggi Agama/IAIN, Jakarta: Proyek Pengembangan Sistem Pendidikan Agama Departemen Agama RI, 1975.

Yudi Cahyono, Bambang, Kristal-Kristal Ilmu Bahasa, cet. I, Surabaya: Airlangga University Press, 1995.

Tayyar Yusuf dan Saiful Anwar, Metodologi Pengajaran Agama dan Bahasa Arab, cet. I, Jakarta: Raja Grafindo Persada, 1995.

Wright T., Roles of Teachers and Learners, Oxford: Oxford University Press, 1987. 